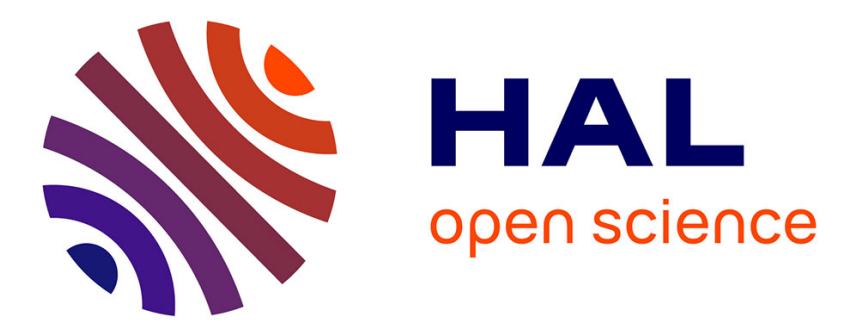

\title{
Smooth muscle of the male pelvic floor: an anatomic study
}

K Nyangoh Timoh, J Deffon, D Moszkowicz, C Lebacle, M Creze, J

Martinovic, M Zaitouna, D Diallo, V Lavoue, A Fautrel, et al.

\section{- To cite this version:}

K Nyangoh Timoh, J Deffon, D Moszkowicz, C Lebacle, M Creze, et al.. Smooth muscle of the male pelvic floor: an anatomic study. Clinical Anatomy, 2020, 33 (6), pp.810-822. 10.1002/ca.23515 . hal-02397615

\section{HAL Id: hal-02397615 https://hal-univ-rennes1.archives-ouvertes.fr/hal-02397615}

Submitted on 18 Dec 2019

HAL is a multi-disciplinary open access archive for the deposit and dissemination of scientific research documents, whether they are published or not. The documents may come from teaching and research institutions in France or abroad, or from public or private research centers.
L'archive ouverte pluridisciplinaire HAL, est destinée au dépôt et à la diffusion de documents scientifiques de niveau recherche, publiés ou non, émanant des établissements d'enseignement et de recherche français ou étrangers, des laboratoires publics ou privés. 


\section{ORIGINAL ARTICLE}

\section{Smooth muscle of the male pelvic floor: an anatomic study}

K. Nyangoh Timoh ${ }^{1,2}$, J. Deffon ${ }^{1}$, D. Moszkowicz ${ }^{1}$, C. Lebacle ${ }^{1,3}$, M.D, M. Creze ${ }^{1}$, J. Martinovic ${ }^{4}$, M. Zaitouna ${ }^{1}$, D. Diallo ${ }^{1}$, V. Lavoue ${ }^{2}$, A. Fautrel ${ }^{5}$, G. Benoit ${ }^{1}$, T. Bessede ${ }^{1,3}$.

\section{Affiliations}

${ }^{1}$ UMR 1195, University Paris Sud, INSERM, Université Paris-Saclay, 94270, Le Kremlin-Bicetre,

France

${ }^{2}$ Department of Obstetrics and Gynecology, Hopital Universitaire de Rennes, university Rennes 1, Rennes, France.

${ }^{3}$ Urology Department, Hopitaux Universitaires Paris-Sud, APHP, 94270, Le Kremlin-Bicetre, France

${ }^{4}$ Department of Fetal Pathology, Hopitaux universitaires Paris-Sud, APHP, 92140, Clamart, France ${ }^{5}$ Université de Rennes 1, Rennes, France; INSERM, UMR991 Liver Metabolism and Cancer, Rennes, France.

\section{Correspondence to :}

Dr Krystel NYANGOH TIMOH, MD.

INSERM-UMR 1195 Hôpital de Bicêtre, Bâtiment Grégory Pincus, 80 rue du Général Leclerc, 94276 Le Kremlin-Bicêtre Cedex, France

Tel: 0331495918 83; E-mail: k.nyangoh@gmail.com

\section{Smooth muscle of the male pelvic floor: an anatomic study}

\section{Abstract}

Introduction: Knowledge of the anatomy of the male pelvic floor is important to avoid damaging the pelvic floor muscles during surgery. We set out to explore the structure and innervation of the smooth muscle of the whole pelvic floor using male fetuses.

Material and Methods: We removed en-bloc the entire pelvis of three male fetuses. The specimens were serially sectioned before being stained with Masson's trichrome and hematoxylin and eosin, and immunostained for smooth muscles, and somatic, adrenergic, sensory and nitrergic nerve fibers. Slides were digitized for 3D reconstruction. 
Results: We individualized a middle compartment that contains smooth muscle (SM) cells. This compartment is in close relation with the levator ani muscle (LAM), rectum, and urethra. We describe a posterior part of the middle compartment posterior to the rectal wall and an anterior part anterior to the rectal wall. The anterior part is split into 1) a centro-levator area of SM cells localized between the right and left LAM, 2) an endo-levator area that upholsters the internal aspect of the LAM, and 3) an infra-levator area below the LAM. All these areas are innervated by autonomic nerves coming from the inferior hypogastric plexus. The core and the infra-levator area receive the cavernous nerve and nerves supplying the urethra.

Conclusion: We thus demonstrate that these muscular structures are smooth and under autonomic influence. These findings are relevant for the pelvic surgeon, and especially the urologist, during radical prostatectomy, abdominoperineal resection and intersphincteric resection.

Key words: levator ani- neuro-anatomy - surgery - pelvic floor - smooth muscle - rectum - proctectomy prostatectomy - anal canal - male - urethra. 


\section{Abbreviations list}

CGRP: calcitonin gene related protein

CRL: crown rump length

IHP: Inferior hypogastric plexus

LAM: Levator ani Muscle

nNOS: neural isoform of nitric oxide synthase

PS100: Protein S100

SM: smoot muscle

SMA: smooth muscle actin

SMMC: Smooth muscle of the middle compartment

TH: Tyrosine Hydroxylase

Vacht: vesicular acetylcholine transferase 


\section{Introduction}

Genito-urinary dysfunctions, such as erectile dysfunction and urinary incontinence, occur respectively in 10 to $46 \%$ and $16 \%$ of patients after radical prostatectomy (Ficarra et al., 2012a; Ficarra et al., 2012b). They may be induced by lesions of the cavernous nerves or of the nerves that supply the urethra after passing through the rectourethral muscle (Costello et al., 2004; Strasser et al., 2000; Takenaka et al., 2005). The relationship between nerve injury and muscle injury is unclear but it is anatomically relevant to study the nerve supply and the targeted muscles together. Knowledge of the anatomy of the male pelvic floor is thus important to avoid damaging the pelvic floor muscles during surgery. Recently, two anatomic studies described the presence of smooth muscle (SM) within the male pelvic floor (Muro et al., 2018; Wu et al., 2018). Wu introduced the concept of "the smooth muscle of the middle compartment" (SMMC) in the urogenital triangle, i.e., between the urethra and the rectum (Muro et al., 2018; Wu et al., 2018).

However, complete studies of the whole male pelvic floor (i.e., laterally and posteriorly to the rectum) are lacking. Moreover, to date no study has detailed the innervation of the SMMC with a view to clarifying its function.

Olassically, autonomic nerves are reported to run above the levator ani muscle (LAM) and somatic nerves below (Benoit et al., 1999). We have previously described communications between the pudendal nerve and the inferior hypogastric plexus (IHP) (Alsaid et al., 2011), and dual autonomic (IHP) and somatic control (pudendal nerve) of pelvic viscera with a communicating loop within the LAM (Alsaid et al., 2011). Subsequently, in two previous studies based on female human fetuses with 3D reconstruction, our team reported that the medial and posterior part of the LAM was smooth and under autonomic nerve control coming from the IHP (Nyangoh Timoh et al., 2017; Nyangoh Timoh et al., 2018).

Therefore, we hypothesized that the SMMC within the male pelvic floor muscle is extensive and controlled by the autonomic system. Thus, the aim of the present study was to describe the SMMC 


\section{Methods}

\section{Material and Methods}

\section{Human fetuses}

The fetal specimens were obtained from late miscarriages. All parents gave written consent and authorization for the scientific use of the cadaver. Only specimens without maceration and without morphologic or neurologic macroscopic abnormalities on pathology examination were used. No infectious conditions were reported and no abnormalities of the central nervous system were observed during the autopsy of the fetuses.

The French Biomedicine Agency approved the study (PFS15-011). The work was compliant with the provisions of the 2013 revised version of the Declaration of Helsinki.

Three male fetuses were selected for study. Fetal age was determined from the crown rump length (CRL) and fetal heel-to-toe length, corrected for the first-trimester ultrasound CRL measurement and confirmed by postmortem examination estimating organ maturation. We analyzed the whole pelvis of three male human fetuses with a CRL of 150-185 mm. Fetuses A and B were at 23 weeks of gestation, and fetus $\mathrm{C}$ at 40 weeks of gestation.

The external body aspect of each fetus was carefully restored after the autopsy out of respect and in case the parents expressed a wish to see their fetus once more.

\section{Macroscopic dissection}

The entire pelvis was removed en-bloc with the pelvic organ and pelvic bone, and was fixed in formalin (10\% formaldehyde) for $48 \mathrm{~h}$. The tissues were then cut into transverse or sagittal slices at 4-mm intervals. The tissue slices were placed in baskets, processed, and embedded in cardboard molds filled with paraffin. To avoid alteration of the visceral topographic relationship, the slices were kept warm in water at $37^{\circ} \mathrm{C}$ and then mounted whole on Superfrost glass slides. They were then dried at $37^{\circ} \mathrm{C}$ overnight. Series of $5 \mu \mathrm{m}$-thick sections 
were then created without intervals. We obtained a total of 150-320 sections from each fetus, depending on the age and size of the specimen.

\section{Staining and immunolabeling}

The first section of each level was taken as the reference and was stained with Masson's trichrome or hematoxylin and eosin $(\mathrm{H} \& \mathrm{E})$ to provide information about the topography and localization of anatomic structures. Smooth muscles were detected with polyclonal antibodies against alpha-Smooth Muscle Actin ( $\alpha-$ SMA) (Kobayashi et al., 2005) (Table 1).

Neuronal markers were detected with polyclonal antibodies against protein S100 (PS100) for all nerves and peripheral myelin protein (PMP 22) for the somatic peripheral nervous system (Bremer et al., 2010); tyrosine hydroxylase (TH) for adrenergic nerves (Butler-Manuel et al., 2002); the neural isoform of nitric oxide synthase (nNOS) for the pro-erectile nerve bundles; and the calcitonin gene-related peptide (CGRP) for primary sensory neuropeptide immunolabelling (Moszkowicz et al., 2011) (Table 1).

Every tenth section was treated according to the following sequences:

(1) The first section was stained with Masson's trichrome or H\&E (annex 1).

The second was used to study smooth muscle with smooth anti-actin polyclonal antibody.

(3) The third was used to study nerves by immunolabeling with anti-protein S100.

(4) The fourth was used to study nerves by immunolabeling with anti-peripheral myelin protein (PMP 22).

(5) The fifth was used to study nerves by immunolabeling with anti-tyrosine hydroxylase antibody $(\mathrm{TH})$.

(6) The sixth was used to study nerves by immunolabeling with an anti-neural isoform of nitric oxide synthase (anti-nNos).

The remaining non-immunolabeled sections were stored for further additional investigations. 
The avidin-biotin-peroxidase detection procedure was carried out with a Vectastain $\mathrm{ABC}$ kit (ref. PK6100; Vector Laboratories, Burlingame, CA, USA). Chromogenic detection was performed with a DAB detection kit (DAB, ref. SK-4100; Vector Laboratories, Burlingame, CA, USA). Non-immune serum or IgG at an equivalent dilution was used as a control for all immunohistochemical analysis.

\section{Histologic examination}

Serial stained and immunolabeled two-dimensional (2D) sections were used for threedimensional (3D) reconstruction. The various anatomic structures (organs, bones, and fascia) were visible under high magnification $(4 \times$ to $40 \times)$ analysis of the Masson's trichrome and H\&Estained sections. Subsequent sections, treated with an antibody against S100, were used to identify the pelvic-perineal nerves and communicating branches. By comparing the Masson's trichrome-stained sections with sections stained with specific antibodies against $\alpha-$ SMA, S100, TH, PMP22, nNOS, and CGRP it was possible to determine the structure of the muscle (smooth (SMA) or striated (myogenin)) and the nature of the nerve fibers identified: i.e., somatic (PMP22), autonomic (TH, VAChT), or nitrergic (nNOS).

The sections were taken at almost the same level with a negligible interval between sections $(5 \mu \mathrm{m})$. The computer system comprised a personal laptop computer (Windows XP) equipped with an Epson Perfection V750 digitization system, Silverfast AI digitization software (Ref B11B178071), Adobe Photoshop image-processing software, and Surfdriver software for Windows (Winsurf image reconstruction software, version 4.3). All sections were digitized at a resolution of 4800 dots per inch, and the images were then stacked and aligned. The brightness and contrast of the histologic tissue images were adjusted using Adobe Photoshop ${ }^{\mathrm{TM}}$. The pelvic anatomic structures and nerve fibers were outlined manually on all histologic sections. A 3D analysis of the location, course, and distribution of the nerve fibers and muscle structure was 
then carried out. To realize the reconstruction, sections stained with Masson's trichrome and/or H\&E, and by anti-PS100 and anti-SMA were used. 


\section{Results}

\section{Global anatomy of the male pelvic floor muscles}

The pubovisceral and puborectal part of the LAM are attached anteriorly to the pubis. The puborectal part of the LAM forms a muscle loop behind the rectum. A bulge of the medial aspect of each pubovisceral muscle between the urethra and rectum is medially linked to the contralateral bulge by a central SM mass that is located between the urethra and the rectum (Fig. 1 and Fig. 2).

The iliococcygeal part of the LAM is attached to the internal obturator muscle by the conjunctive tissue of the tendinous arch of the LAM (Fig. 1A, 1B, and 1C).

The deep transverse perineal muscle lies below the LAM. The superficial transverse perineal muscle is anterior to the deep transverse perineal muscle and lateral to the bulbospongiosus muscle.

\section{Spatial distribution of smooth muscle areas within the male pelvic floor}

We individualized a middle compartment that contains SM cells. This compartment is in close relation with the LAM, rectum, and urethra (Fig. 1A, 1B, 1C, and 1D). We will describe it posteriorly and anteriorly to the anterior rectal wall:

\section{The posterior part of the middle compartment:}

From the sacrum to the rectum, an SM layer upholsters the internal aspect of the LAM with SM $d^{\prime}$ igitations into the rectal wall. Laterally, this layer is continuous with the anterior part of the middle compartment, and more specifically with the endo-levator area (Fig. 1 and Fig. 2).

\section{The anterior part of the middle compartment:}

Using the LAM as an anatomic landmark, three areas can be described:

1. The centro-levator area. A "core" of SM cells is localized between the right and left LAM in the transversal plane, and between the rectum and urethra in the sagittal plane. At its cranial pole, the core is in continuity with the external longitudinal layer of the rectum (Fig. 1 and Fig. 2).

2. The endo-levator area. An SM layer upholsters the internal aspect of the LAM. On both sides of the SM layer, digitations anchor the layer within the rectum internally and within 
the LAM externally. The endo-levator area corresponds to the medial part of the LAM and to the external anal sphincter (Fig. 1 and Fig. 2).

3. The infra-levator area. SM cells lie in a fan shape below the LAM and infero-posteriorly to the endo-levator area (Fig. 1).

Ventrally to the "SM-core" (sagittal and transversal sections), these three areas merge in the extension of the bulbospongiosus muscle and of the internal urethral sphincter. (Fig. 2 and Fig. 3)

Laterally to the "SM-core" (coronal reconstruction and transversal sections) the endo- and infralevator areas cover the LAM (Fig. 1 and Fig. 2). These SM expansions can be described to fins of the SM-core (Fig. 1).

All of the above-described SM structures of the anterior and posterior parts are in continuity with each other and can be defined as a "smooth muscle middle compartment" (SMMC) of the male pelvic floor.

\section{Innervation of the smooth muscle area}

The SM areas are innervated by autonomic nerves which arise from the IHP. The IHP is comprised of hypogastric and pelvic splanchnic nerves. It is possible to individualize retro-rectal, latero-rectal, inter-prostato-rectal, latero-prostatic, and antero-prostatic fibers (Fig. 4A et Fig. 5D).

The distal part of the IHP is localized in a triangular zone between the LAM laterally, the urethra anteriorly and the rectum posteriorly. The nerves (positive S100 antibody labeling) are: sympathetic (positive TH antibody), sensory (positive CGRP antibody), and nitrergic (positive NOS antibody). There are no somatic nerves (negative PMP22 antibody) (Fig. 5).

\section{The posterior part of the SMMC}

The nerves of the posterior part of the SMMC are retro-rectal and come from the IHP. Some fibers continue to the rectum and others terminate in the posterior part (Fig. 5 and Fig. 6).

\section{The anterior part of the SMMC}

Nerve fibers come from the IHP complex. 
1. The centro-levator area: Inter-prostato-rectal and latero-prostatic nerves pass through the endo-levator area of the anterior part of the SMMC (Fig. 5C, 6A, 6B, and 6D). The area is characterized by dense innervation: several nerves pass through this region to reach the posterior face of the internal urethral sphincter or continue towards the erectile bodies. (Fig. $4 \mathrm{C}, 4 \mathrm{D}, 6 \mathrm{~A}, 6 \mathrm{~B}$ and 6D)

2. The endo-levator area: This area is innervated by nerve fibers from the lateral wall of the rectum. Some provide innervation to the rectum following digitations of the endo-levator area within the rectum. Others innervate the prostate. (Fig. 5G and 5H).

3. The infra-levator area: Nerve fibers are latero-rectal, inter-prostato-rectal and lateroprostatic. Some provide innervation for the rectum. Some nerves pass through this region to reach the posterior face of the internal urethral sphincter or continue towards the erectile bodies. Others innervate the infra-levator area. (Fig. 4D and 6C). 


\section{Innervation of striated muscles}

The striated muscle is innervated by the pudendal nerve and the levator ani nerve.

Contribution of the pudendal nerve:

The pudendal nerve passes through the pudendal canal. Proximally, the pudendal nerves are somatic (positive PMP22 antibody) and sympathetic (positive TH antibody), but not CGRP or NoS positive. The perineal branches of the pudendal nerve innervate the inferior part of the puborectal, pubovisceral and iliococcygeal muscles, the ischiocavernosus muscle and the bulbospongiosus muscle, as well as the superficial transverse perineal muscle (Fig. 5). Terminal perineal branches of the pudendal nerve are sympathetic (positive TH antibody), and somatic (positive PMP22 antibody). They are also nitrergic (positive NOS antibody) and sensory (positive CGRP antibody) (Fig. 7).

Contribution of the levator ani nerve:

The fibers run horizontally in the pelvis and then vertically to take a pre-rectal and latero-prostatic pathway. They innervate the superior part of the LAM. (Fig. 7) The fibers are somatic (positive PMP22 antibody), sympathetic (positive TH antibody), sensory (positive CGRP antibody), and n'trergic (positive NOS antibody) (Fig. 7).

\section{Summary}

The SMMC of the male pelvic floor is a continuous area surrounding the pelvic organs. It is anchored laterally into the striated muscular structures and medially into the pelvic and perineal viscera. The SMMC is under autonomic influence contrary to the lateral striated muscles that are under somatic control. We provide a video of the male pelvic floor of the fetus B (supporting information) 


\section{Discussion:}

The findings of the current study support the existence of the SMMC: a middle muscle compartment formed by smooth muscle behind (posterior part) and in front of (anterior part) the rectum. These smooth muscles are continuous and connected to the LAM, the rectum and the internal urethral sphincter. The present study also suggests that the SMMC contains a high density of autonomic nerves coming from the IHP.

The human fetal model has previously been used to study pelvic muscle and neuroanatomy. This model offers many advantages over surgical dissection. First, the small size of the fetus pelvis enables en-bloc removal and en-bloc processing with mega-cassette embedding, and data loss and structure displacement is limited. Consequently, the whole neuro-anatomy and muscular pelvic floor (i.e., anterior and posterior to the rectum) can be studied as muscular insertions are preserved. Moreover, 3D reconstruction is easier and faster and there is less reconstruction bias. Second, the nerve diameter/body ratio is higher in the fetus versus the adult thus simplifying neuroanatomy observations. Third, the use of very fresh tissue means that multiple specific muscular and neuronal markers can be used to provide functional results.

In an effort to systematize our description, we considered the SMMC as a whole and named its different parts according to their relationship with the LAM. This topographic denomination illustrates and highlights the common histology of these structures. However, when referring to anatomic literature, which includes several descriptions of the muscular architecture of the male urogenital region, one has to make the connection with other terminologies (Aigner et al., 2004; Brooks et al., 2002; Fritsch, 1989; Muro et al., 2018; Nakajima et al., 2007; Porzionato et al., 2005; Smith, 1908; Wu et al., 2018; Zhai et al., 2011)

Similarly to previous authors, we observed a central mass coming from the anterior longitudinal layer of the rectum. We chose to describe this mass as a "centro-levator area" because of its very central position in the pelvic floor between the two sides of the LAM or a "core" in relation to its 
compact aspect. Due to the presence of a loose smooth muscle cell connection between this "centrolevator area" and the external and internal urethral sphincter, bulbourethral gland and bulbospongiosus muscle, the centro-levator area may correspond a structure that has successively been called: the rectourethral (Brooks et al., 2002; Porzionato et al., 2005; Uchimoto et al., 2007) muscle, the recto-perineal (Aigner et al., 2004; Sebe et al., 2005) muscle, or the deep transverse perineal muscle (Oelrich, 1980).

We also observed SMs running antero-inferiorly to the LAM which we describe as an "infra-levator area". They are linked to "the centro-levator area" and connected to the external wings of the urethral sphincter (Nakajima et al., 2007), the bulbourethral gland, and the bulbospongiosus muscle. Muro et al. described a lateral extension of the rectourethral muscle located anteroinferiorly to the LAM as the deep transverse perineal muscle (Muro et al., 2018). Our results illustrate that the "infra-levator area" does indeed correspond to the deep transverse perineal muscle. Although many discrepancies remain about the smooth or skeletal nature of the muscle and about the existence of the deep transverse perineal muscle (Kokoua et al., 1993; Murakami et al., 2002; Nakajima et al., 2007; Uchimoto et al., 2007; Zhai et al., 2011), our description is consistent with Henle, Muro et al., and Zhai et al. (Henle; Muro et al., 2018; Zhai et al., 2011).

We describe the SM located medially to the LAM and to the external anal sphincter as an "endolevator area". We have already referred to this structure in the female as the medial part of the LAM (Nyangoh Timoh et al., 2018). This area directly connects the rectum and the LAM. Shafik called it the hiatal ligament (Shafik, 1999), and Arakawa et al. the smooth muscle-mediated interface (Arakawa et al., 2010).

The part posterior to the rectum, the posterior part, also contained smooth muscle cells and forms the posterior part of the endo-levator area. It corresponds to the anococcygeal ligament that goes from the coccyx to the anus between the slings of the LAM (Kinugasa et al., 2012; Kinugasa et al., 2011; Muro et al., 2014; Shafik, 1975). Muro et al. already reported smooth muscle cells behind the rectum (Muro et al., 2014). 
As Muro et al., we preferred not to use the term "perineal body" in the results section, as we considered that it probably refers to the region between the urethra and rectum rather than a structure per se (Larson et al., 2010; Muro et al., 2018).

Most studies to date describe the pelvic floor smooth muscle area separately, sometimes using different terms for the same structure. Few report smooth muscle cells behind the rectum. Here, we provide evidence for continuous abundant smooth muscle fibers within the whole pelvic floor (in front of and behind the rectum).

A few authors have published data about the innervation of the muscles of the pelvic floor (Costello et al., 2004; Strasser et al., 2000; Takenaka et al., 2005). Classically, the somatic nerves are reported to run below the LAM and the autonomic nerves above (Benoit et al., 1999). However, our team have already provided data about autonomic-somatic communications within the LAM (Alsaid et al., 2011). Moreover, we recently published data about autonomic innervation of the medial and posterior part of the female LAM (Nyangoh Timoh et al., 2017). Here, we provide evidence for autonomic innervation coming from the IHP of the SMMC in the male. The posterior part is innervated by retro-rectal nerves and the endo-levator part by latero-rectal nerves. More interestingly, the centro-levator and infra-levator areas (i.e., rectourethral muscle and deep transverse perineal muscle) are important nerve pathways supplying the internal urethral sphincter and erectile bodies (cavernous nerves) as suggested by Strasser et al. (Strasser et al., 2000). Our results are consistent with the study of Takenaka et al. (Takenaka et al., 2005). However, unlike the study we present here, none of these previous authors used specific neuronal markers. We were able to distinguish autonomic sensory and highly nitrergic nerves supplying the SMMC.

From a physiopathologic point of view, the presence of abundant SM linking the external striated muscles of the pelvic viscera and the pelvic viscera itself may not be circumstantial. The close connection to the LAM suggests that it may be part of a mechanism playing a major role in pelvic floor stability by providing lifting power (DeLancey, 1993). Furthermore, as the SMMC comes from the anterior longitudinal layer of the rectum in the sagittal direction, we can hypothesize that it 
participates in the anorectal flexure (Wesson, 1922) and consequently to fecal continence. Moreover, the SMMC is innervated by autonomic nerves from the IHP. These data point towards the possibility that the SMMC plays a dynamic role with simultaneous contraction under autonomic nerve impulse leading to urinary and fecal continence. Finally, we cannot exclude the possibility that the SMMC plays a protective or regenerative role (Arakawa et al., 2004).

From a clinical point of view, we believe that a better understanding of the path of the cavernous nerve and the nerve supplying the internal urethral sphincter is of importance for pelvic surgeons. In the field of urology, protecting erectile function and urinary continence during radical prostatectomy is a challenge. A recent study highlighted that cavernous nerve preservation improves both erectile function and urinary continence (Reeves et al., 2015). Because the centroand infra-levator areas (i.e., the rectourethral muscle and deep transverse perineal muscle) are crossed by both the cavernous nerve and the nerve supplying the urethra, these areas are veritable minefields during radical prostatectomy. In order to spare these nerves, Takenaka et al. recommend incising the rectourethral muscle close to the rectum during perineal prostatectomy, and near the prostatic apex during retropubic prostatectomy (Takenaka et al., 2005). However, surgeons must be aware that the rectouretralis muscle comes from the anterior extension of the rectal wall. Indeed up to $11 \%$ of rectal injuries occur during radical perineal prostatectomy (Lassen and Kearse, 1995). Nerve sparing is also a challenge in the field of abdominal surgery. In their study, Uchimoto et al. observed that Denonvilliers' fascia ended in the rectouretralis muscle, and thus proposes taking the surgical plane behind Denonvilliers' fascia when possible (Uchimoto et al., 2007).

Knowing that both the rectourethral and deep transverse perineal muscles are SM that are connected with the urethra is also of major importance: damage to these muscles may result in postoperative urethral incontinence.

Despite these results, this study has some limitations which are mainly linked to the use of the fetal model. For example, one could argue that the pelvic structure is not fully formed in the fetus. However, previous studies have reported that the pelvic muscular and neuroanatomy of the fetus is 
mature at 8 weeks of gestation (Arango-Toro and Domenech-Mateu, 1993; Fritsch et al., 2004). Second, the very small number of specimens could lead to bias. However, we used three fetuses with different axes of section (two sagittal and one axial) to add different observation angles. Moreover, the results were consistent in all three fetuses. 


\section{Conclusion}

We provide evidence that the rectourethral muscle, deep transverse perineal muscle and anococcygeal raphe have common features: they are of smooth muscle nature and autonomic innervation, and they are closely linked to each other and with the pelvic viscera and striated muscle - thus forming an anatomic and functional entity which can be called the SMMC. Nevertheless, the precise function of the SMMC remains to be defined. 


\section{References}

Aigner F, Zbar AP, Ludwikowski B, Kreczy A, Kovacs P, Fritsch H. 2004. The rectogenital septum: morphology, function, and clinical relevance. Dis Colon Rectum 47:131-140.

Alsaid B, Moszkowicz D, Peschaud F, Bessede T, Zaitouna M, Karam I, Droupy S, Benoit G. 2011. Autonomic-somatic communications in the human pelvis: computer-assisted anatomic dissection in male and female fetuses. J Anat 219:565-573.

Arakawa T, Hayashi S, Kinugasa Y, Murakami G, Fujimiya M. 2010. Development of the external anal sphincter with special reference to intergender difference: observations of mid-term fetuses (15-30 weeks of gestation). Okajimas Folia Anat Jpn 87:49-58.

Arakawa T, Murakami G, Nakajima F, Matsubara A, Ohtsuka A, Goto T, Teramoto T. 2004. Morphologies of the interfaces between the levator ani muscle and pelvic viscera, with special reference to muscle insertion into the anorectum in elderly Japanese. Anat Sci Int 79:72-81.

Arango-Toro O, Domenech-Mateu JM. 1993. Development of the pelvic plexus in human embryos and fetuses and its relationship with the pelvic viscera. Eur J Morphol 31:193-208.

Benoit G, Droupy S, Quillard J, Paradis V, Giuliano F. 1999. Supra and infralevator neurovascular pathways to the penile corpora cavernosa. J Anat 195 ( Pt 4):605-615.

Bremer J, Baumann F, Tiberi C, Wessig C, Fischer H, Schwarz P, Steele AD, Toyka KV, Nave KA, Weis J, Aguzzi A. 2010. Axonal prion protein is required for peripheral myelin maintenance. Nat Neurosci 13:310-318.

Brooks JD, Eggener SE, Chao WM. 2002. Anatomy of the rectourethralis muscle. Eur Urol 41:94100.

Butler-Manuel SA, Buttery LD, A'Hern RP, Polak JM, Barton DP. 2002. Pelvic nerve plexus trauma at radical and simple hysterectomy: a quantitative study of nerve types in the uterine supporting ligaments. J Soc Gynecol Investig 9:47-56.

Costello AJ, Brooks M, Cole OJ. 2004. Anatomical studies of the neurovascular bundle and cavernosal nerves. BJU Int 94:1071-1076.

DeLancey JO. 1993. Anatomy and biomechanics of genital prolapse. Clin Obstet Gynecol 36:897909.

Ficarra V, Novara G, Ahlering TE, Costello A, Eastham JA, Graefen M, Guazzoni G, Menon M, Mottrie A, Patel VR, Van der Poel H, Rosen RC, Tewari AK, Wilson TG, Zattoni F, Montorsi F. 2012a. Systematic review and meta-analysis of studies reporting potency rates after robot-assisted rddical prostatectomy. Eur Urol 62:418-430.

Ficarra V, Novara G, Rosen RC, Artibani W, Carroll PR, Costello A, Menon M, Montorsi F, Patel VR, Stolzenburg JU, Van der Poel H, Wilson TG, Zattoni F, Mottrie A. 2012b. Systematic review and meta-analysis of studies reporting urinary continence recovery after robot-assisted radical prostatectomy. Eur Urol 62:405-417.

Fritsch H. 1989. Topography of the pelvic autonomic nerves in human fetuses between 21-29 weeks of gestation. Anat Embryol (Berl) 180:57-64.

Fritsch H, Lienemann A, Brenner E, Ludwikowski B. 2004. Clinical anatomy of the pelvic floor. Adv Anat Embryol Cell Biol 175:Iii-ix, 1-64.

Henle J. Handbuch der systematischen anatomie des menschen.

Kinugasa Y, Arakawa T, Abe H, Abe S, Cho BH, Murakami G, Sugihara K. 2012. Anococcygeal raphe revisited: a histological study using mid-term human fetuses and elderly cadavers. Yonsei Med J 53:849-855.

Kinugasa Y, Arakawa T, Abe S, Ohtsuka A, Suzuki D, Murakami G, Fujimiya M, Sugihara K. 2011. Anatomical reevaluation of the anococcygeal ligament and its surgical relevance. Dis Colon Rectum 54:232-237.

Kobayashi M, Inoue K, Warabi E, Minami T, Kodama T. 2005. A simple method of isolating mouse aortic endothelial cells. Journal of atherosclerosis and thrombosis 12:138-142. 
Kokoua A, Homsy Y, Lavigne JF, Williot P, Corcos J, Laberge I, Michaud J. 1993. Maturation of the external urinary sphincter: a comparative histotopographic study in humans. J Urol 150:617622.

Larson KA, Yousuf A, Lewicky-Gaupp C, Fenner DE, DeLancey JO. 2010. Perineal body anatomy in living women: 3-dimensional analysis using thin-slice magnetic resonance imaging. Am J Obstet Gynecol 203:494.e415-421.

Lassen PM, Kearse WS, Jr. 1995. Rectal injuries during radical perineal prostatectomy. Urology 45:266-269.

Moszkowicz D, Alsaid B, Bessede T, Zaitouna M, Penna C, Benoit G, Peschaud F. 2011. Neural supply to the clitoris: immunohistochemical study with three-dimensional reconstruction of cavernous nerve, spongious nerve, and dorsal clitoris nerve in human fetus. J Sex Med 8:11121122.

Murakami G, Nakajima F, Sato TJ, Tsugane MH, Taguchi K, Tsukamoto T. 2002. Individual variations in aging of the male urethral rhabdosphincter in Japanese. Clin Anat (New York, NY) $15: 241-252$.

Muro S, Tsukada Y, Harada M, Ito M, Akita K. 2018. Spatial distribution of smooth muscle tissue in the male pelvic floor with special reference to the lateral extent of the rectourethralis muscle: Application to prostatectomy and proctectomy. Clin Anat (New York, NY) 31:1167-1176. Muro S, Yamaguchi K, Nakajima Y, Watanabe K, Harada M, Nimura A, Akita K. 2014. Dynamic intersection of the longitudinal muscle and external anal sphincter in the layered structure of the anal canal posterior wall. Surg Radiol Anat : SRA 36:551-559.

Nakajima F, Takenaka A, Uchiyama E, Hata F, Suzuki D, Murakami G. 2007. Macroscopic and histotopographic study of the deep transverse perineal muscle (musculus transversus perinei profundus) in elderly Japanese. Ann Anat 189:65-74.

Nyangoh Timoh K, Bessede T, Lebacle C, Zaitouna M, Martinovic J, Diallo D, Creze M, Chevallier JM, Darai E, Benoit G, Moszkowicz D. 2017. Levator ani muscle innervation: Anatomical study in human fetus. Neurourol Urodyn 36:1464-1471.

Nyangoh Timoh K, Moszkowicz D, Zaitouna M, Lebacle C, Martinovic J, Diallo D, Creze M, Lavoue V, Darai E, Benoit G, Bessede T. 2018. Detailed muscular structure and neural control anatomy of the levator ani muscle: a study based on female human fetuses. Am J Obstet Gynecol 218:121.e121-121.e112.

Oelrich TM. 1980. The urethral sphincter muscle in the male. Am J Anat 158:229-246.

Porzionato A, Macchi V, Gardi M, Parenti A, De Caro R. 2005. Histotopographic study of the rectourethralis muscle. Clin Anat (New York, NY) 18:510-517.

Reeves F, Preece P, Kapoor J, Everaerts W, Murphy DG, Corcoran NM, Costello AJ. 2015. Preservation of the neurovascular bundles is associated with improved time to continence after radical prostatectomy but not long-term continence rates: results of a systematic review and metaanalysis. Eur Urol 68:692-704.

Sebe P, Oswald J, Fritsch H, Aigner F, Bartsch G, Radmayr C. 2005. An embryological study of fetal development of the rectourethralis muscle--does it really exist? J Urol 173:583-586.

Shafik A. 1975. New concept of the anatomy of the anal sphincter mechanism and the physiology of defecation. II. Anatomy of the levator ani muscle with special reference to puborectalis. Invest Urol 13:175-182.

Shafik A. 1999. Levator ani muscle: new physioanatomical aspects and role in the micturition mechanism. World J Urol 17:266-273.

Smith GE. 1908. Studies in the Anatomy of the Pelvis, with Special Reference to the Fasciae and Visceral Supports: Part II. J Anat Physiol 42:252-270.

Strasser H, Ninkovic M, Hess M, Bartsch G, Stenzl A. 2000. Anatomic and functional studies of the male and female urethral sphincter. World J Urol 18:324-329.

Takenaka A, Murakami G, Matsubara A, Han SH, Fujisawa M. 2005. Variation in course of cavernous nerve with special reference to details of topographic relationships near prostatic apex: histologic study using male cadavers. Urology 65:136-142. 
Uchimoto K, Murakami G, Kinugasa Y, Arakawa T, Matsubara A, Nakajima Y. 2007.

Rectourethralis muscle and pitfalls of anterior perineal dissection in abdominoperineal resection and intersphincteric resection for rectal cancer. Anat Sci Int 82:8-15.

Wesson MB. 1922. AN ANATOMICAL AND EMBRYOLOGICAL STUDY OF THE PERINEUM. Cal State J Med 20:269-272.

Wu Y, Dabhoiwala NF, Hagoort J, Hikspoors J, Tan LW, Mommen G, Hu X, Zhang SX, Lamers WH. 2018. Architecture of structures in the urogenital triangle of young adult males; comparison with females. J Anat 233:447-459.

Zhai LD, Liu J, Li YS, Ma QT, Yin P. 2011. The male rectourethralis and deep transverse perineal muscles and their relationship to adjacent structures examined with successive slices of celloidinembedded pelvic viscera. Eur Urol 59:415-421. 
Table 1: Primary polyclonal antisera

\begin{tabular}{|c|c|c|c|c|c|c|c|c|}
\hline $\begin{array}{l}\text { Antigen } \\
\text { (abbreviation) }\end{array}$ & Code & Tissue target & $\begin{array}{l}\text { Antigen } \\
\text { retrieval }\end{array}$ & $\begin{array}{l}\text { Incuba- } \\
\text { tion }\end{array}$ & $\begin{array}{l}\text { Positive } \\
\text { Control }\end{array}$ & Species & Dilution & Provider \\
\hline $\begin{array}{l}\text { Protein S100 } \\
\text { (PS100) }\end{array}$ & Z0311 & All nerves & non & $1 \mathrm{~h}$ & $\begin{array}{l}\text { Sacral } \\
\text { plexus }\end{array}$ & rabbit & $1 / 400$ & $\begin{array}{l}\text { Dako; } \\
\text { Denmark }\end{array}$ \\
\hline $\begin{array}{l}\text { calcitonin } \\
\text { gene related } \\
\text { peptide } \\
\text { (CGRP) }\end{array}$ & $\begin{array}{l}03- \\
16008\end{array}$ & $\begin{array}{l}\text { Sensory } \\
\text { nerves }\end{array}$ & $\begin{array}{l}\text { Citrate } \\
\text { buffer }\end{array}$ & $12 \mathrm{~h}$ & $\begin{array}{l}\text { Human thyroid } \\
\text { gland }\end{array}$ & rabbit & $1 / 200$ & $\begin{array}{l}\text { ARP, } \\
\text { American } \\
\text { research } \\
\text { products, } \\
\text { USA }\end{array}$ \\
\hline $\begin{array}{l}\text { Tyrosine } \\
\text { Hydroxylase } \\
\text { (TH) }\end{array}$ & ab112 & $\begin{array}{l}\text { Autonomic } \\
\text { Sympathetic } \\
\text { nerves }\end{array}$ & $\begin{array}{l}\text { Citrate } \\
\text { buffer }\end{array}$ & $12 \mathrm{~h}$ & $\begin{array}{l}\text { Supra- } \\
\text { renal } \\
\text { gland }\end{array}$ & rabbit & $1 / 750$ & $\begin{array}{l}\text { abcam; } \\
\text { USA }\end{array}$ \\
\hline $\begin{array}{l}\text { The neural } \\
\text { isoform of } \\
\text { nitric oxide } \\
\text { synthase } \\
\text { (nNOS) }\end{array}$ & 160870 & $\begin{array}{l}\text { Pro-erectile } \\
\text { nerves }\end{array}$ & no & $12 \mathrm{~h}$ & $\begin{array}{l}\text { Human adult } \\
\text { cavernous } \\
\text { nerve }\end{array}$ & rabbit & $1 / 200$ & $\begin{array}{l}\text { Cayman; } \\
\text { USA }\end{array}$ \\
\hline $\begin{array}{l}\text { Peripheral } \\
\text { Myelin } \\
\text { Protein (PMP } \\
\text { 22) } \\
\end{array}$ & ab61220 & $\begin{array}{l}\text { Somatic peripheral } \\
\text { nerves }\end{array}$ & no & $12 \mathrm{~h}$ & $\begin{array}{l}\text { Human thyroid } \\
\text { gland }\end{array}$ & rabbit & $1 / 100$ & abcam; USA \\
\hline $\begin{array}{l}\text { Smooth muscle } \\
\text { actin (SMA) }\end{array}$ & ab15267 & Smooth muscle & no & $10 \mathrm{~min}$ & $\begin{array}{l}\text { Human } \\
\text { colon }\end{array}$ & rabbit & $1 / 150$ & $\begin{array}{l}\text { abcam; } \\
\text { USA }\end{array}$ \\
\hline
\end{tabular}




\section{Figure Legends:}

Figure 1: Serial sagittal sections of a 23-week-old male fetus and serial transverse sections of another 23-week-old male fetus. It was scanned at an optical resolution of $4800 \mathrm{dpi}$.
(A) Serial sagittal section stained with Eosin Haematoxylin.
(B), (C) Serial sagittal section stained with anti-smooth muscle actin antibody.
(C) is the same section as (B) with legends.
(D), (E), (F), (G) Serial transverse sections stained with anti-smooth muscle actin antibody.

Sequential sections from cranial (D) to distal (F) poles showing the emergence of the centro-levator area, "the core" (light green arrows).

$(\mathrm{G})$ is the same section as $(\mathrm{F})$ with legends.

Code: Endo-levator area (ENDO): purple; Centro-levator area (CENTRO): light green; Infralevator (INFRA): light blue; Piriformis muscle (PM), Internal obturator muscle (IOM) : dark brown; Bladder: yellow; Urethra (ur) : yellow, Levator ani muscle (LAM) : orange; External anal sphincter (EAS): dark blue; Prostate : dark red; Rectum: beige; Bulbourethral gland: grey; Bulbospongiosus muscle: pink. 
Figure 2: Computer-assisted anatomic dissection (CAAD) of the morphologic pelvic structure in a 23-week-old male fetus.
(A) (B) Reconstruction of the SMMC
(C) Reconstruction of the SMMC and levator ani muscle.
(D) Reconstruction of the SMMC, the rectum, the bulbospongiosus muscle (BSM), the external anal sphincter (EAS), the levator ani muscle, the internal urethral sphincter and the prostate.

(E) Right lateral view of the three-dimensional reconstruction.

(F) Superior view of the three-dimensional reconstruction.

Code: Endo-levator area (ENDO) and the posterior part: purple; Centro-levator area (CENTRO): light green; Infra-levator area (INFRA): light blue; Levator ani muscle (LAM): orange; External anal sphincter (EAS): dark blue; Prostate: dark red; Rectum: beige; Bulbospongiosus muscle (BSM): pink; External urethral sphincter (US): light purple. 


\section{Fig 4: Serial transverse sections of a 23-week-old male fetus}

(A), (A bis) Transverse sections stained with anti-S100 antibody.

Code : Retro-rectal nerve fibers (RETRO-RECTAL): dark purple, latero-rectal nerve fibers (LATERO-RECTAL): beige, inter-prostato-rectal nerve fibers (INTER-PROSTATO-

RECTAL): purple, latero-prostatic (LATERO-PROSTATIC): orange, and antero-prostatic fibers (ANTERO-PROSTATIC): light beige.

(B) (Bbis) Transverse sections stained with anti-SMA antibody.

Code: Endo-levator area (ENDO): purple; the Centro-levator area (CENTRO): light green; Levator ani muscle (LAM): orange; Rectum: beige; External urethral sphincter (EUS): light purple.

(C) (Cbis) (D) (Dbis)Transverse sections stained with anti-S100 antibody.

(D) (Dbis) are magnifications of (C) and (Cbis) respectively.

Code: Nerves from IHP: light yellow, perineal branches of pudendal nerve: dark green.

\section{Fig 5: Serial sagittal sections of a 23-week-old male fetus}

(A) (B) (A1) (B1) Sagittal sections stained with anti-SMA antibody.

Code: Endo-levator area (ENDO): purple; Centro-levator area (CENTRO): light green; Infra-levator (INFRA): light blue; Piriformis muscle (PM), Internal obturator muscle (OIM) : dark brown; Bladder: yellow; Urethra (ur) : yellow, Levator ani muscle (LAM) : orange; External anal sphincter (EAS): dark blue; Prostate : dark red; Rectum: beige.

(C) (C1) (D) (D1) Sagittal sections stained with anti-S100antibody.

Code : Retro-rectal nerve fibers (RETRO-RECTAL): dark purple, Latero-rectal nerve fibers (LATERO-RECTAL): beige, Inter-prostato-rectal nerve fibers (INTER-PROSTATO-

RECTAL): purple, Latero-prostatic (LATERO-PROSTATIC): orange, and Antero-prostatic fibers (ANTERO-PROSTATIC): light beige. (E) (E1) Sagittal section stained with antiPMP22 antibody. 
(F) (F1) Sagittal section stained with anti-TH antibody.

(G) (G1) Sagittal section stained with anti-NOS antibody.

(H) (H1) Sagittal section stained with anti-CGRP antibody.

(A1) (B1) (C1) (D1) (E1) (F1) (G1) (H1) are magnifications of (A) (B) (C) (D) (E) (F) (G)

(H) respectively.

Black arrowheads show somatic nerves (E) (E1), autonomic sympathetic nerves (F) (F1), nitrergic nerves $(\mathrm{G}),(\mathrm{G} 1)$ and sensitive nerves $(\mathrm{H}),(\mathrm{H} 1)$.

Fig 6: Computer-assisted anatomic dissection (CAAD) of the morphologic pelvic structure and the innervation in a 23 weeks-old male fetus.

(A), (B) Reconstruction of the SMMC, levator ani muscle, autonomic and somatic innervation.

(A) Anterior view and (B) right lateral view.

(C), (D) Reconstruction of the SMMC, levator ani muscle, prostate and urethral sphincter autonomic and somatic innervation.

(C) Posterior view and (D) superior view.

Code: Endo-levator area (ENDO) and the posterior part: purple; Centro-levator area (CENTRO): light green; Infra-levator area (INFRA): light blue; Levator ani muscle (LAM): orange; External anal sphincter (EAS): dark blue; Prostate: dark red; Rectum: beige; Bulbospongiosus muscle (BSM): pink; External urethral sphincter (EUS): light purple, Pudendal nerve: green, Levator ani nerve: blue, Inferior hypogastric plexus : yellow.

Fig 7: Serial sagittal sections of a 23-week-old male fetus

(A) (B) (A1) (B1) (A2) (B2) Sagittal sections stained with anti-S100 antibody.

(C) (C1) (C2) Sagittal section stained with anti-PMP22 antibody.

(D) (D1) (D2) Sagittal section stained with anti-TH antibody.

(E) (E1) (E2) Sagittal section stained with anti-NOS antibody. 
(F) (F1) (F2) Sagittal section stained with anti-CGRP antibody.

(A1) (B1) (C1) (D1) (E1) (F1) are magnifications of (A) (B) (C) (D) (E) (F) respectively showing the levator ani nerve.

(A2) (B2) (C2) (D2) (E2) (F2) are magnifications of (A) (B) (C) (D) (E) (F) respectively showing the pudendal nerve.

Black arrows show somatic nerves (E) (E1), autonomic sympathetic nerves (F) (F1), nitrergic nerves $(\mathrm{G}),(\mathrm{G} 1)$ and sensitive nerves $(\mathrm{H}),(\mathrm{H} 1)$.

Code: Levator ani muscle: orange; Rectum : beige, Pudendal nerve : blue; Levator ani nerve : green.

\section{Annex legend}

Annex 1: Serial transverse sections of another 23-week-old male fetus. It was scanned at an optical resolution of 4800 dpi.

Black arrowhead shows the tendinous arch of the LAM.

Code: Internal obturator muscle (IOM): dark brown; Urethra (ur): yellow, Levator ani muscle (LAM) : orange. 


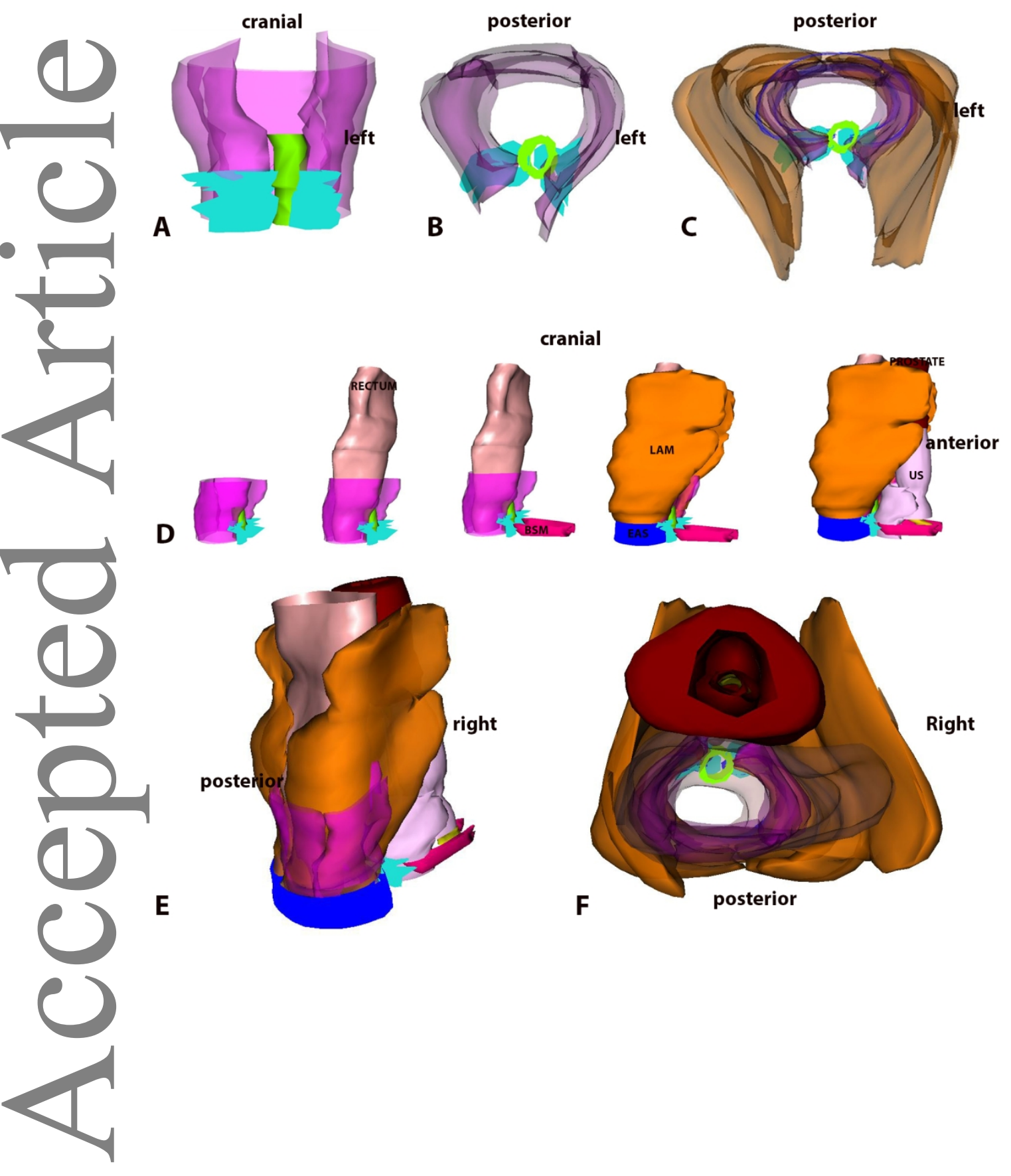




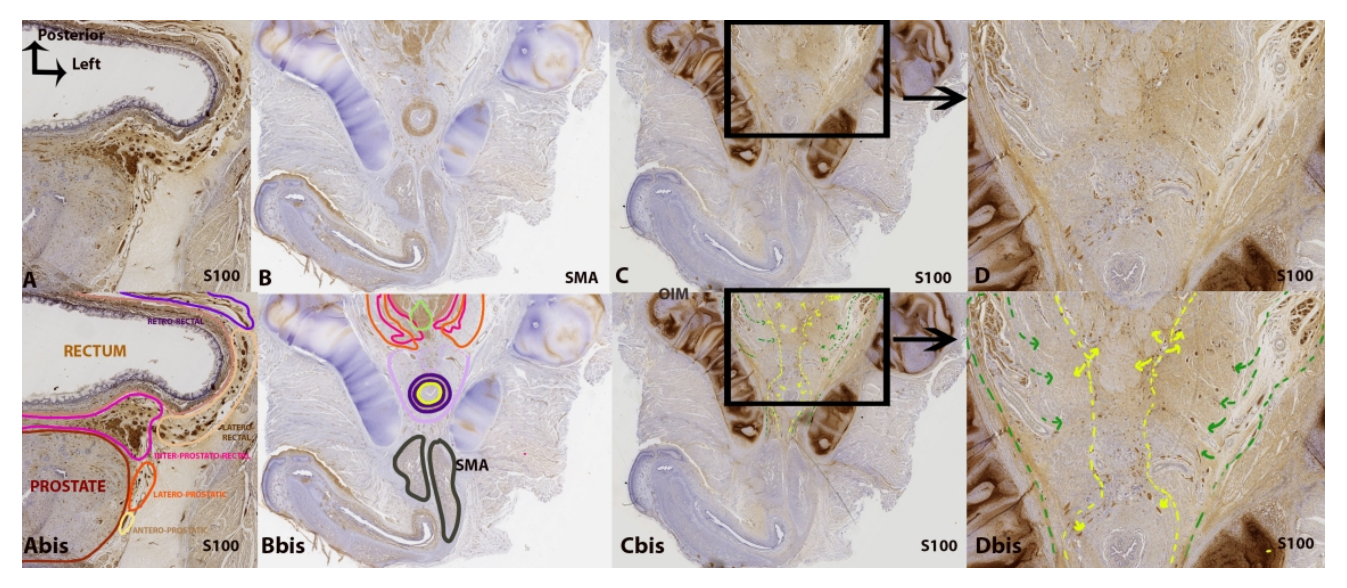




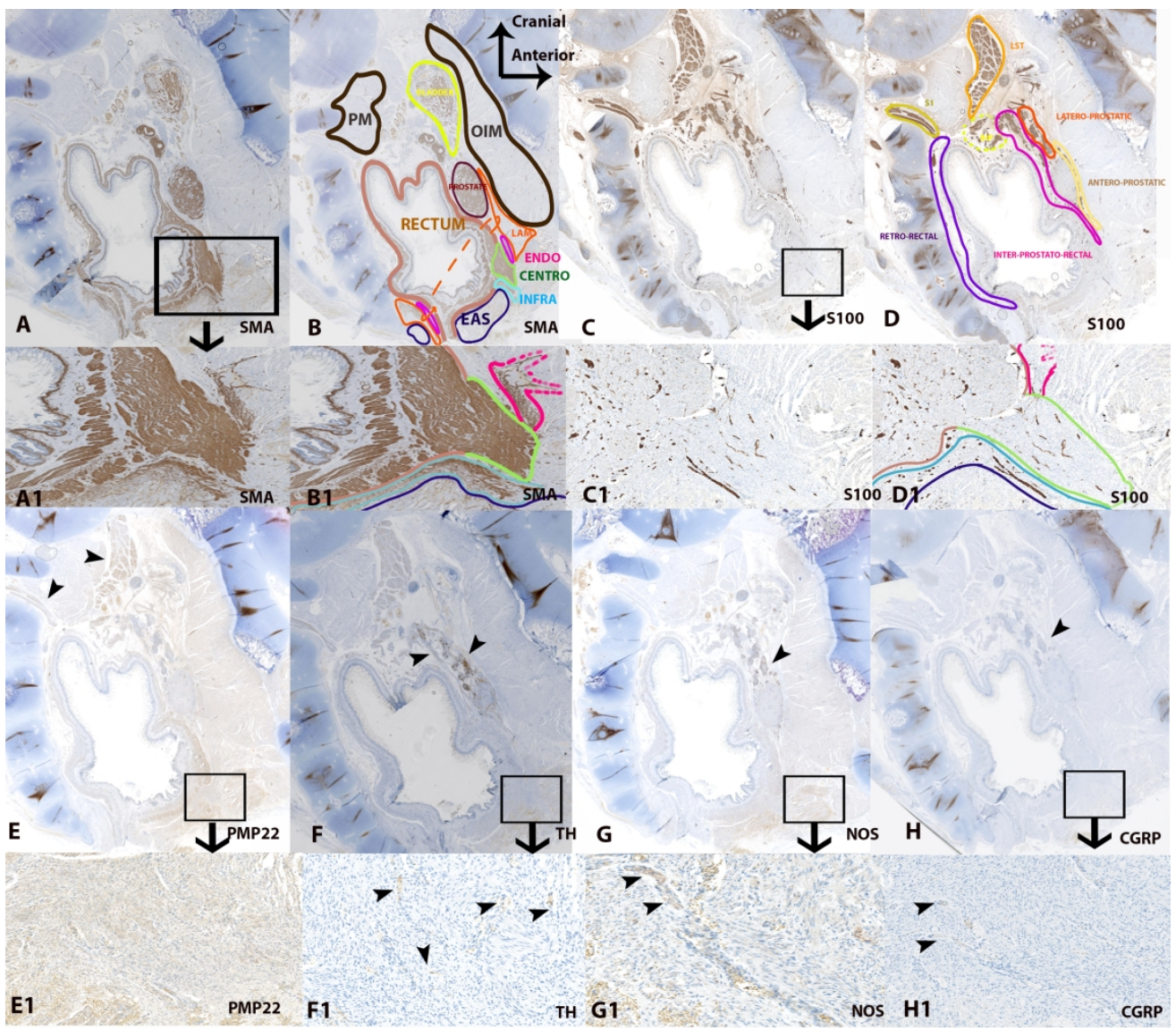



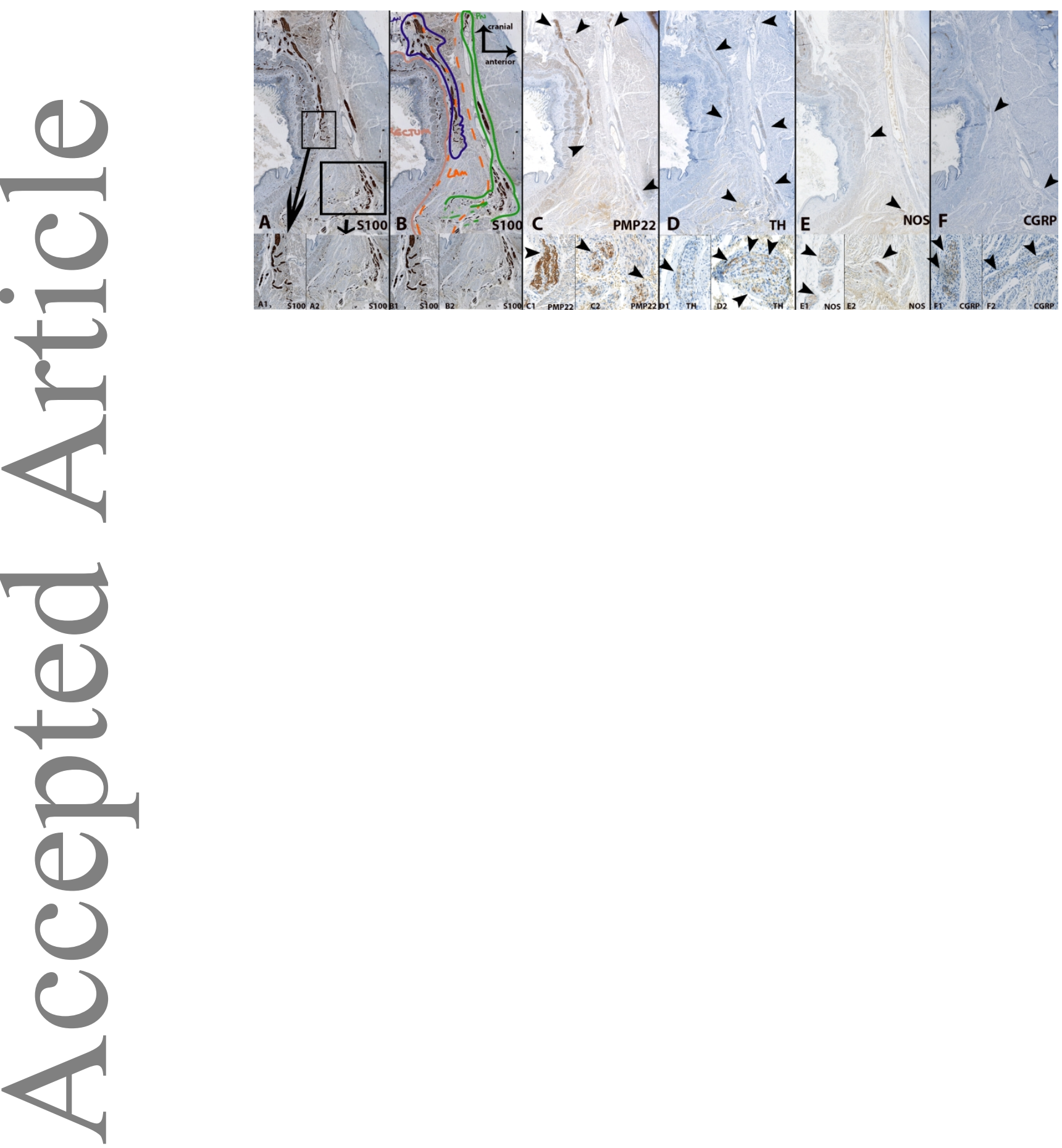
